\title{
Modelling of stylolite geometries and stress scaling
}

\author{
${ }^{\mathrm{a}}$ Koehn, D., ${ }^{\mathrm{b}}$ Ebner, M., ${ }^{\mathrm{c}}$ Renard, F., ${ }^{\mathrm{d}}$ Toussaint, R., ${ }^{\mathrm{e}}$ Passchier, C.W.
}

${ }^{a}$ School of Geographical and Earth Sciences, University of Glasgow, Gregory building, Lilybank Gardens, Glasgow G12 8QQ, UK

${ }^{\mathrm{b}}$ Geological Survey of Austria, Neulinggasse 38, A1030 Vienna, Austria

${ }^{\mathrm{c}}$ CNRS-Observatoire, Université Joseph Fourier BP 53, F-38041 Grenoble, France \& Physics of Geological Processes, University of Oslo, Norway

${ }^{\mathrm{d}}$ Institut de Physique du Globe de Strasbourg (IPGS), CNRS and University of Strasbourg (EOST), 5 rue Descartes, F-67084 Strasbourg Cedex, France

${ }^{\mathrm{e}}$ Tectonophysics, Institute of Geosciences, Johannes Gutenberg University, Becherweg 21, 55099 Mainz, Germany

\section{Abstract}

4

In this contribution we present numerical simulations of stylolite growth to decipher the effects of initial rock heterogeneity and stress on their morphology. We show that stylolite growth in a rock with a uniform grain size produces different patterns than stylolite growth in a rock with a bimodal grain size distribution. Strong pinning of large heterogeneities produce stylolite structures that are dominated by pronounced teeth, whereas a uniform grain size leads to spikes and a roughness that shows variable wavelengths. We compare the simulated stylolites with natural examples and show that the model can reproduce the real structures. In addition we show that strong pinning in the bimodal case can lead to a linear stylolite roughness growth in contrast to the non-linear growth of stylolites that develop from a uniform noise. In a set of 24 simulations we vary the main principle stress on the stylolite in order to test if our model can reproduce the analytically derived stress-scaling proposed by Schmittbuhl et al. (2004). We compare the calculated stresses with the applied stresses and show that the numerical model and the analytical solution are in good agreement. Our results strengthen the hypothesis that stylolites can be used as strain and stress gauges to estimate not only the orientation of paleo-stresses, but also their absolute values of formation stresses and amounts of compaction. 
Keywords: stylolite, stress-gauge, compaction, pressure solution, numerical model, selfaffinity

\section{Introduction}

Pressure solution is an important deformation mechanism that takes place in the upper parts of the Earth's crust (Rutter, 1983). This mechanism of dissolution, transport and precipitation of material starts as shallow as $90 \mathrm{~m}$ during diagenesis in sedimentary basins (Tada \& Siever 1989) and may still be active during high grade metamorphic conditions (Beach, 1979). If the dissolution of material takes place in a localized manner, rough dissolution surfaces develop that are termed stylolites (Fig. 1, Dunnington, 1954; Heald, 1955; Park \& Schot, 1968; Guzzetta, 1984; Merino, 1992; Railsback, 1993; Karcz \& Scholz, 2003). Stylolites are very common in a variety of mono-mineralic rock types and have several distinct characteristics: they concentrate material that cannot be dissolved as fast as the matrix appearing as dark seams, the surface has a pronounced roughness of peaks or spikes with parallel or inward sloping sides, such that they can be pulled apart without breaking the rock; and this roughness occurs on a range of scales (Fig. 1).

Geologists are interested in stylolites because they are used to estimate the compaction and the stress history in sedimentary basins (Ebner et al. 2009b, Petit \& Mattauer 1995, Rispoli 1981). The hydrocarbon industry is mainly interested in stylolites because they affect reservoir properties; they can be sealing because of their clay content and reduce porosity and permeability around the stylolite, while they may also act as channel-ways when fluids travel along the stylolite interface (Fabricius \& Borre, 2007; Baron \& Parnell, 2007). The use of stylolites to estimate compaction and stress is of great interest to Earth scientists and may be used for basin analysis or tectonic studies in fold and thrust belts. Reliable paleo-stress gauges are rare in geology. For several reasons we are convinced that stylolites can play this role: (1) Stylolites are very common geological structures and (2) the orientation of their teeth track 
the direction of the main compressive stress, (3) the magnitude of these asperities capture part of the compaction history of the host-rock and (4) it has been demonstrated that the stylolite roughness can be used to estimate absolute stress values, i.e. the mean, differential and the principal stress values (Ebner et al., 2009b, 2010a). A few other paleo-stress markers exist, as e.g. the study of calcite twins in rocks (Burkhard. 1993, Lacombe, 2010), but they are generally more sensitive to the stress orientation than to its magnitude. It is useful to develop additional paleo-stress gauges, which can be applied on a variety of rocks, such as stylolites that are present in many sedimentary rocks.

\section{The use of stylolites for structural analysis}

Stylolite morphology develops according to two main processes. Firstly, an interface can either be initially present in the sediment, such as the interface between two different sedimentary layers or a fracture, or they form by propagation from an initial site of stress concentration that promotes the formation of an anticrack (Fletcher and Pollard, 1981), localize due to chemical effects induced by micas (Aharonov and Katsman 2009) or localized volume reduction (Katsman et al. 2006). Secondly, such interface may roughen with time, a process that is dependent on local stress conditions and the amount of heterogeneities in the rock. Stylolites can be used in structural analysis to find three parameters: the main compressive stress direction (e.g. Rispoli, 1981, Koehn et al. 2007), the amount of compaction and the product of the differential and mean stress (Ebner et al, 2009b, Ebner et al. 2010a). Stylolite teeth (Fig. 2a) are thought to grow parallel to the main compressive stress direction, a hypothesis that was strengthened by recent numerical simulations (Ebner et al. 2009a, Koehn et al. 2007). These simulations show that the lateral position of a tooth along a stylolite interface is random but its shape is strongly deterministic with respect to the orientation of the direction of maximum finite compaction, which is identical with the main compressive stress orientation in homogeneous solids. The amplitude of a stylolite can be 
used indirectly to calculate the amount of compaction. Although this can be difficult, the nonlinear scaling relationship between finite compaction and average stylolite amplitude gives reasonable estimates (Koehn et al. 2007). Without the use of a scaling function one can estimate the amount of dissolved material at the stylolite by using its maximum height, but this requires the observation of this maximum in a few spots, which can be hidden in the rock in some situations. Hence, the maximum height observed corresponds to a lower bound of the dissolution (amount of compaction along the stylolite) that took place, and not necessarily the total one. The scaling function given by Koehn et al. (2007) can be used to estimate compaction; however the function is non-linear leading to a relatively large uncertainty in the result.

The third and most important value that can be determined from natural stylolites is the product of the differential and mean stress, which can be calculated from the scaling of the stylolite roughness (Renard et al., 2004), based on an analytical solution presented in Schmittbuhl et al. (2004). This analytical solution demonstrates that the stresses acting during stylolite formation can be derived from the stylolite roughness hidden in the crossover-length scale that separates two self-affine scaling regimes well documented for natural stylolites. Ebner et al. (2009b) showed in a study on natural bedding parallel stylolites, which were sampled at different depths in a sedimentary basin, that the measured principal normal stress value increases linearly with the depth of stylolite formation, which supports the analytical solution. These authors also present a method that allows the calculation of the full paleostress tensor from the stylolites under favourable conditions. In addition Ebner et al. (2010a) show with a study on tectonic stylolites that these can reveal the difference between all three principal stress components, which is an additional support for the theory of Schmittbuhl et al. (2004).

In order to further test the hypothetical scaling relation of the stylolite roughness as a function to overburden stress, we present two-dimensional numerical simulations of the roughness 
development of a set of sedimentary stylolites and their sensitivity to stress. First we present

110 different stylolite geometries that develop in a limestone with a constant grain size versus a

111 limestone with a bimodal distribution of grains (or fossils). Then we test the analytical

112 solution of Schmittbuhl et al. (2004) and show with a numerical model (Koehn et al., 2007)

113 how stylolites can be used to attain the full paleo-stress tensor and the paleo-depth of

114 (bedding parallel) stylolite growth in a sedimentary basin. In addition we validate our

115 numerical simulations by showing that they result in stylolite geometries found in nature and

116 we show that the model reproduces the crossover length scale that is predicted by the solution

117 of Schmittbuhl et al. (2004) for a given stress.

\section{3. The stress gauge}

120 Detailed measurements of stylolite roughness (Renard et al. 2004, Ebner et al. 2009b), as well

121 as deterministic models of stylolite formation (Schmittbuhl et al. 2004, Koehn et al. 2007)

122 indicate that the absolute value of the stress can be determined from the roughness of a

123 stylolite. Stylolites are thought to roughen because of the existence of heterogeneities in a

124 rock that dissolve at different rates than the host-rock. In limestone, these heterogeneities may

125 be fossils on a millimetre scale or clay particles, oxide or quartz grains on a micrometer scale.

126 Impurities are localizing dissolution and in some cases enable stylolite formation (Aharonov

127 and Katsman, 2009) and collect within the stylolite surface during successive stress driven

128 dissolution of the host-rock. The host-rock dissolves on both sides of the stylolite. If this

129 dissolution is locally heterogeneous, so that one part of the host-rock on one side of the

130 stylolite dissolves slower than the other, the interface starts to become rough (Fig. 2a,b). In an

131 extreme case an impurity like an oxide grain can pin one side of the stylolite host-rock

132 completely, so that this side does not dissolve at all. The pinning particle is then quasi pushed

133 into the host-rock on the other side of the stylolite and a spike develops. For example, Ebner 
et al. (2010b) have shown with an EBSD analysis that small quartz grains pin corners of some

135 stylolite teeth (Fig. 2c).

136 The developing stylolite roughness can be accurately described by a self-affine scaling

137 function with a characteristic Hurst or roughness exponent (Brouste et al. 2007, Gratier et al.

138 2005, Renard et al. 2004, Schmittbuhl et al. 2004). When a rough surface shows a self-affine

139 property, its roughness has a variable amplitude (A) over wavelength $(\lambda)$ ratio at different

140 scales. A self-affine 1D profile can be described mathematically as invariant under self affine

141 transformations, i.e. anisotropic zooms of any pair of factors $\left(b, b^{\alpha}\right)$, where $\mathrm{b}$ is real,

142 respectively for the sub-parallel and normal direction to the average surface: A zoom

143 transformation on the surface in the $\mathrm{x}$-direction by $x \rightarrow b x$ and in height by $h \rightarrow b^{\alpha} h$, where $\mathrm{x}$

144 is oriented parallel to the stylolite interface, $\mathrm{h}$ is the height of the interface, $\mathrm{b}$ is a linear

145 scaling factor and $\alpha$ the Hurst or roughness exponent (Barabasi \& Stanley 1995). If the

146 roughness exponent is smaller than 1.0 the profile is called self-affine: it appears flat on the

147 large scale and rougher (with larger aspect ratio $\mathrm{A} / \lambda$ of out of plane amplitude over in plane

148 wavelength) on the small scale. Such a scaling is reproduced by the natural stylolite shown in

149 Figure 1, where the stylolite seems flat on the larger scale (Fig. 1a, width $40 \mathrm{~cm}$, low ratio

$150 \mathrm{~A} / \lambda$ ) and appears progressively rougher on the small scale (Fig. 1c,d, width $6 \mathrm{~cm}$ and $4 \mathrm{~mm}$,

151 higher ratio $\mathrm{A} / \lambda$ ). Natural stylolites tend to show not only one but two characteristic

152 roughness exponents. On the large scale the exponent is around 0.5 whereas on the small

153 scale it is close to 1 (Renard et al., 2004, Schmittbuhl et al. 2004). The change from one

154 scaling regime to the other (characterized by different scaling exponents) is relatively sharp. It

155 lies typically on the millimetre length scale and is termed crossover-length $(l)$. An interface

156 with a roughness exponent of about 1.0 is called self-similar, and does not change its

157 roughness aspect ratio $\mathrm{A} / \lambda$ with different scales, which can also be seen in Figure $1 \mathrm{c}, \mathrm{d}$, where

158 the amplitude over wavelength ratio does not change significantly (width $4 \mathrm{~mm}$ and $0.8 \mathrm{~mm}$ ). 
159 Schmittbuhl et al. (2004) could show with their analytical solution that these two roughness

160 exponents correspond to two different thermodynamic regimes where surface energy is

161 dominant on the small scale and elastic energy dominant on the large scale, with a well-

162 defined cross-over length at the millimetre scale.

163 It is important to notice that surface and elastic energies tend to flatten the interface whereas

164 the heterogeneities initially present in the host rock i.e. a quenched noise roughen the

165 interface (Koehn et al. 2007, Schmittbuhl et al. 2004). The surface energy in the rock stays

166 constant whereas the elastic energy is a function of the stress field surrounding the stylolite.

167 When the stress increases because the stylolite grows for example in deeper parts of a

168 sedimentary basin the elastic energy also increases and the cross-over between surface and

169 elastic energy dominated regimes shifts to smaller scales. Hence the influence of surface

170 energies is shifted to smaller scales with increasing stress. Determining the cross-over from

171 natural stylolites thus gives a value for the stress on the stylolite interface. The scaling

172 relation from Schmittbuhl et al. (2004) relates the cross-over length scale $(l)$ with the product

173 of the mean $\left(\sigma_{m}\right)$ and differential $\left(\sigma_{\text {dif }}\right)$ stress according to

174

$$
l=\frac{\gamma E}{\beta} \frac{1}{\sigma_{m} \sigma_{d i f}}
$$

175 where $\gamma$ is the surface free energy, $E$ the Young's modulus and $\beta$ a function of the Poisson

176 ratio $(\beta=v(1-2 v) / \pi)$. In a sedimentary basin with a uniaxial vertical stress component (i.e.

177 zero horizontal displacements) and the horizontal components being a function of the vertical

178 stress component $\sigma_{z}$, equation (1) simplifies to (modified after Ebner et al. 2009b)

$$
l=\frac{\gamma E}{\kappa} \frac{1}{\sigma_{z}^{2}}
$$

180 where $\kappa$ is a function of the Poisson ratio $\left(\kappa=\frac{v}{3 \pi} \frac{(1-2 v)^{2}(1+v)}{(1-v)^{2}}\right)$. This scaling relation is only valid for bedding parallel stylolites (sedimentary stylolites), for which the principal 
182 horizontal stresses are equal if one assumes no lateral displacement. For tectonic stylolites

183 with 3 different main compressive stresses this solution cannot be applied since in that case 184 the differential stresses vary. An approximation for the complex tectonic case is given in

185 Ebner et al. (2010a). In the present contribution we want to test the scaling relation for

186 sedimentary stylolites with the numerical simulations of Koehn et al. (2007) and illustrate

187 how the stylolite morphology varies with increasing depth in a sedimentary basin. This 188 comparison between natural data (Ebner et al., 2009b), an analytical model (Schmittbuhl et 189 al., 2004) and numerical simulations will allow us to propose that stylolites can be used as 190 stress gauges.

\section{Numerical model}

193 We use the numerical model of Koehn et al. (2003, 2006, 2007), Bons et al. (2008) and 194 (Ebner et al. 2009a). It is based on a 2D linear elastic lattice spring model where elements can 195 dissolve as a function of surface energy, elastic energy and normal stress at the interface. 196 Dissolution takes place at a predefined surface that is initially smooth (Fig. 3). Particles on the 197 interface are stressed when they are in contact. We calculate the surface energy at the 198 interface and the elastic energy of the particle (Koehn et al., 2007) and use these in addition to 199 the difference between the normal stress at the particle surface and the average normal stress across all particles at the interface to determine how fast the particle dissolves according to

201 (Koehn et al., 2007)

$$
D_{i}=k_{i} V_{s}\left(1-\exp \left(\frac{-\Delta \sigma_{n} V_{s}-\Delta \psi}{R T}\right)\right),
$$

where $D_{i}$ is the dissolution rate of particle $i, k_{i}$ a rate constant, $V_{s}$ the molecular volume, $\Delta \sigma_{n}$

204 the difference in normal stress along the interface, $\Delta \Psi_{s}$ the difference in Helmholtz free 205 energy of the solid (the sum of elastic and surface energies at a particle) between a curved 206 stressed interface and a flat unstressed interface, $R$ the universal gas constant and $T$ the 
absolute temperature (in Kelvins). Note that we are using the difference in normal stress

208 between the average normal stress on all interface particles and the particle's normal stress.

209 We are not using the stress difference between an unstressed surface and a stressed surface. If

210 we use the difference between an unstressed and a stressed surface the normal stress term is

211 too dominant and the crossover does not appear in the simulations. We assume that the

212 structure is constantly dissolving so that diffusion and precipitation of material are not taken

213 into account. However, since we use the normal stress difference between the average stress

214 and the local stress we model a situation where the fluid has a concentration of dissolved

215 material that is proportional to the average normal stress on the stylolite.

216 Roughening of the surface is induced by randomly oriented slower dissolving particles (5\%)

217 that pin the interface until they themselves dissolve (Fig. 3a). In the case of a bimodal grain

218 size we include slower dissolving larger grains (or fossils), defined by clusters of particles.

219 These clusters themselves contain a noise on a smaller scale, so that they contain particles that

220 dissolve slower than the cluster itself (Fig. 3b). For the presented simulations the numerical

221 model has two resolutions, the smaller resolution of 184000 particles, a real physical width of

$2224 \mathrm{~cm}$ and a particle size of $0.1 \mathrm{~mm}$ is used for simulations that have a noise and grain size on

223 one scale whereas a larger resolution of 736000 particles and a real physical width of $8 \mathrm{~cm}$ is

224 used for simulations with a bimodal distribution of noise and grain size. Additional

225 parameters are a Poisson ratio of 0.33 (determined by the shape of lattice used), a Youngs

226 modulus of $80 \mathrm{GPa}$ and a surface free energy of $0.27 \mathrm{~J} / \mathrm{m}^{2}$ relevant for limestone. The molar

227 volume for calcite is $0.00004 \mathrm{~m}^{3} / \mathrm{mol}$, the temperature is $300 \mathrm{~K}$ and the dissolution constant

228 for calcite is $0.0001 \mathrm{~mol} /\left(\mathrm{m}^{2} \mathrm{~s}\right)$ (Clark, 1966; Renard et al., 2004; Schmittbuhl et al., 2004;

229 Koehn et al., 2007). The deformation is uniaxial with fixed side-walls simulating stylolite

230 formation in a sedimentary basin, the vertical stress is constant for the simulation with a

231 bimodal noise (50 MPa) and is varied between 29 and $92 \mathrm{MPa}(29,41,50,57,64,71,80,92)$

232 for simulations with a noise that is only on the particle scale. 


\section{Results of the simulations}

\subsection{Comparison of natural and simulated stylolites}

236 We use two different initial setups for the simulations, which are illustrated in figure 3. In the 237 first setup we use a random distribution of slower dissolving particles in the model, these are 238 shown as dark particles in figure 3a. In all these simulations 5\% of particles dissolve $20 \%$ 239 slower than the rest. This means that they can pin the surface, but they may dissolve 240 themselves if elastic or surface energies at the tips of spikes become too large or if two slower 241 dissolving particles meet at the interface (Koehn et al., 2007). In the second set of simulations 242 we add larger grains (also 5\%) that dissolve 20\% slower (fig. 3b); they are defined as clusters 243 of particles. These larger grains are added on top of the initial distribution of slower 244 dissolving particles. This means that the slower dissolving grains also contain particles that 245 dissolve slower and the noise is bimodal.

246 The developing geometries are shown in figure 4 where we compare the simulated patterns 247 with natural examples. Figure 4 a shows a stylolite that was simulated when using a bimodal 248 noise. The larger grains at the interface are shown in grey. The stylolite geometry clearly 249 reflects the bimodal nature of the noise. The largest grains pin the interface and result in extreme teeth with very straight edges. The stylolite surface between the large grains shows much smaller roughness amplitude, that slowly develops into larger wavelengths. This surface is on average still in the middle of the stylolite and resembles the orientation of the initially 253 flat interface where dissolution started. The teeth that are pinned by larger grains have 254 variable height depending on when the pinning grains (clusters of slower dissolving particles in our model setup) meet the interface. The surface on top or at the bottom of the teeth shows a roughness that is similar to the normal stylolite roughness indicating that the pinning grains slowly dissolve themselves. The actual dissolution of the host-rock is indicated by the grey 258 bar on the right hand side of the simulated stylolite. One can observe that the distance 
between the highest and lowest teeth on each side of the stylolite almost reflects the actual 260 dissolution. Large grains started to pin the interface relatively early and are not yet completely 261 dissolved so that the actual dissolution is still recorded by the stylolite. The picture on the right hand side shows a stylolite from the "Muschelkalk" limestone of southern Germany where large fossils pin the interface resulting in large teeth. The noise is clearly bimodal and 264 the simulation captures the geometries of the real stylolite.

265 Figure $4 \mathrm{~b}$ shows a simulation with a noise only on the particles and a similar natural stylolite on the right hand side. The simulated stylolite shows the typical geometry that was discussed in Koehn et al. (2007) and Ebner et al. (2009) with the development of variable wavelengths and amplitudes of roughness. Extreme spikes can develop if single particles pin the interface 269 for a long time, meaning that they probably meet no slowly dissolving particle on the other 270 side of the interface. The spikes are not as straight as the teeth that develop when the noise is 271 bimodal (Fig. 4a). The grey bar on the right hand side of the simulated stylolite shows the 272 actual dissolution and illustrate that dissolution is underestimated when the distance between 273 the highest and lowest tip of the spikes on the stylolite are used to estimate compaction. The 274 picture on the right hand side of figure $4 \mathrm{~b}$ shows a stylolite with a geometry that is very 275 similar to the simulation. This indicates that the noise in the natural example has a relatively constant scale and the grain size is probably relatively uniform which is underpinned by

277 microscopic analysis not shown in this study. In general it can be stated that the numerical 278 model can capture the complex geometries of natural stylolite examples. This implies that the 279 model captures the main characteristics of stylolite growth and is realistic.

\subsection{Bimodal noise, stylolite growth and compaction estimates}

282 Figure 5 shows the progressive growth of a stylolite with pronounced teeth for three different 283 time steps, after 2000, 4000 and 6000 model steps. These steps do not correspond to real time 284 but are a function of the vertical strain and thus the compaction applied to the stylolite - these 
corresponds to an average of $\mathrm{xx}$, yy and $\mathrm{zz}$ dissolved particle rows. Large grains that pin the

286 surface are shown in grey and the actual amount of host-rock dissolution is shown in grey 287 bars on the right hand side of the three stylolites. Grains that pin the interface are initially relatively close to the starting dissolution surface so that pinning results already in pronounced teeth in the first time step shown $(\mathrm{t}=2000)$. Parts of these pinning grains survive and pin the surface until the last time step. This means that only initially a small part of the compaction is not recorded by the stylolite but at later stages the teeth record the full amount of dissolved host-rock. This will change once the pinning grains are dissolved themselves and pinning stops. During time steps 2000 and 4000 the stylolite geometry is still controlled by the large pinning grains on the one hand and by the small scale roughness that develops due to pinning on the particle scale. The latter results in the rough stylolite surface in the centre of 296 the stylolite at time step 4000 where a number of wavelengths develop. At time step 6000 the 297 geometry is mainly controlled by the large scale pinning grains since most of these meet with the stylolite interface. Each tip of a tooth contains small rests of these slower dissolving grains. Some of the teeth record almost the full compaction (from one side) because they met 300 the stylolite relatively early and started to grow from the centre of the stylolite. Others, 301 however, do not really record the full compaction since they either met the interface during a 302 later stage of growth or they met an already developing tooth and are now dissolving the hostrock in the other direction. This can be seen for example at time step 2000, when a small grain 304 on the left hand side of the stylolite meets the left corner of a tooth (see arrow in Fig. 5a). The 305 grain is now "pushing" upwards into the host-rock, the developing tooth meets the original 306 orientation of the interface during time step 4000 and moves upwards at time step 6000. One 307 can use the distance between the highest and lowest tooth in such a stylolite to estimate compaction. Note that unless two slower dissolving grains are positioned next to each other

309 but on opposite sides of the stylolite and pin the interface, each stylolite tooth will only record 310 half of the compaction since they start out from one side of the stylolite (Fig. 5). In contrast to 
the non-linear growth of stylolites that grow in more uniform rocks (Koehn et al., 2007 Ebner

312 et al. 2009a), a stylolite with a bimodal noise and strongly pinning grains grows linear with a

313 growth exponent of about 1.0. - up to the moment where slowly dissolving grains would meet

314 and destroy this large teeth growing in a ballistic (or fast) mode, to get more fluctuating peak

315 growth: a transition to a nonlinear growth similar to the more uniform rock type is then

316 expected.

\subsection{Stress scaling}

In the last set of simulations, we perform runs with a uniform noise and vary the stress on the

stylolite. We model stylolites that grew under a vertical stresses of 29, 41, 50, 57, 64, 71, 80 and $92 \mathrm{MPa}$. All stylolite simulations run for 8000 model time steps, each stress state is modelled three times. We then analyze the roughness and try to recover the stress from the stylolite morphology using the crossover length, where we average the results of the three different runs per stress state. Examples of the finite stylolite pattern are shown in Figure 6, where we present two stylolites for each stress state from 29 to $80 \mathrm{MPa}$. Variations in noise in these cases are only a function of a different random seed of quenched noise i.e. the heterogeneities in the system for each simulation.

Figure 6 illustrates the difficulty to see a relationship between the amount of stress that a stylolite experienced and the stylolite roughness directly from the geometry of the roughness. This is also illustrated by the variation in stylolite shape at constant stress depending only on 331 the random distribution of slowly dissolving particles (right versus left hand side in figure 6).

332 There may be a general trend from more wavy stylolites at lower stresses to more spiky stylolites at higher stresses, but this relation is not clear. Therefore one has to use statistical tools in order to analyze the stylolite roughness.

In order to determine the scaling of the interface roughness and cross-over length scale from

336 the simulated and natural stylolites we use the Fourier method (e.g. Barabasi \& Stanley, 1995; 
Schmittbuhl et al., 1995). We calculate the Fourier power spectrum $P(k)$ i.e., the square of the

338 modulus of the Fourier transform, as a function of the wave-number $k$ [1/lengthscale $\left.\left(\mathrm{mm}^{-1}\right)\right]$

339 for each stylolite pattern. For the simulations we take averages of the power spectra of three

340 runs and plot the resulting average power spectrum as a function of $k$ in $\log$-log space. If the 341 roughness is self-affine the plot shows (Fig. 3) a linear slope, which is a function of the Hurst 342 exponent (Renard et al., 2004; Schmittbuhl et al., 2004)

$$
P(k) \sim k^{-1-2 \alpha} .
$$

344 Figure 7a shows the power spectrum as a function of the wave-number for the natural stylolite 345 of figure 1 and figure $7 \mathrm{~b}$ an average of three numerical simulations. Both plots are similar, 346 with the natural data spanning over a wider range of magnitudes than the simulated data but 347 the simulated data having less noise in the signal because it is averaged over three runs. Since 348 the wave-number in the plots is a function of $1 /$ wavelength, the left hand side of the plots 349 represents the larger wavelengths. Here the plots show two slopes, separated by a well350 defined crossover wavelength. These two self-affine regimes correspond to the elastic energy 351 dominated regime at the large scale and the surface energy dominated regime at the small 352 scale. On the very right hand side of the two plots the slope becomes flatter at a length scale 353 comparable to the particle size in the model and the drawn bitmap of the natural example.

354 This flat portion of the signal has to be cut off for the analysis of the cross-over length scale. 355 In order to fit a curve to the graphs we bin the data: it becomes clear in Figure $7 \mathrm{c}$ and $\mathrm{d}$ that in 356 the binned data set the two slopes become more visible. To avoid bias due to improper fitting 357 of the crossover-length that separates the two slopes we use a nonlinear least square curve358 fitting algorithm in logarithmic space (Ebner et al. 2009b) with predefined roughness 359 exponents of 1.1 and 0.5 for the surface energy and elastic dominated regimes, respectively 360 (Ebner et al., 2009b). The resulting cross-over $l$ is then used for further analysis.

361 Figure 8 shows the result of the 24 simulations where the vertical stress component of the 362 simulated stylolites is plotted against the inverse of the square root of the cross-over 
according to the scaling function of equation (2). The determined cross-over in the

364 simulations is clearly a function of the stress on the stylolite and shows the right scaling 365 relation:

$$
\sigma_{z}=a \sqrt{1 / l}
$$

similarly to equation (2), since the boundary condition used in these simulations also correspond to a fixed vertical stress and fixed lateral displacement along $\mathrm{x}$, as the one used to derive equation (2). The slope (a) of the linear regression line of the data is a function of the input parameters in equation (2) of the numerical model. The slope is almost identical with the input parameters of the numerical model (square root of Young's modulus times surface energy divided by $\kappa$ ), which shows that the scaling relation derived analytically and presented by Schmittbuhl et al. (2004) is verified by the numerical stylolite morphologies and is

374 independently produced by the current numerical model presented here. This thus constitutes 375 another completely independent check of this analytical expression, after the comparison of 376 the overload stresses with the one determined from the crossover length for the stylolites 377 investigated by Ebner et al. (2009b) in Southern France.

\section{Methodology and application to natural cases}

380 As an example for a paleo-stress calculation, we can use the natural stylolite shown in Figure 3811 and the determined cross-over in Figure 7c. The calculation gives a vertical stress of about $38234 \mathrm{MPa}$, a horizontal stress of about $13 \mathrm{MPa}$, a mean stress of $23.5 \mathrm{MPa}$ and a differential 383 stress of $21 \mathrm{MPa}$. If we assume that the overlying sediments in the basin had a density of 384 about $2.5 \mathrm{~kg} / \mathrm{cm}^{3}$, the paleo-depth of the stylolite was about $1400 \mathrm{~m}$ in the basin. The 385 orientation of the teeth or spikes of the stylolite indicates that the direction of the main compressive stress was vertical and that the stylolite formed in the sedimentary basin during

387 burial. A limit with these calculations will always be the uncertainty in the input parameters 
like the Young's Modulus, Poisson's ratio and the surface free energy at the time of stylolite

389 formation. We used a relatively high Young's Modulus for the numerical simulations (80

$390 \mathrm{GPa}$ ). The real limestone may have a lower value of about $50 \mathrm{GPa}$ and this would change the

391 stress and depth estimates (26.5 MPa vertical stress and $1100 \mathrm{~m}$ overburden). It is always

392 advisable to use a range of natural stylolites for depth estimates as proposed in the work of

393 Ebner et al. (2009b). In addition to the stress calculation, one can estimate the amount of 394 dissolved material at the stylolite. According to the presented simulations the stylolite shown 395 in figures 1 and $4 \mathrm{~b}$ (right hand side) developed in a host-rock with a relatively uniform grain 396 size. If the stylolite grew in a similar way than the simulations (Fig. 4b) then the dissolved 397 material at the interface is in the order of $3 \mathrm{~cm}$. However, since the grain size in the natural 398 example is about $1 / 10^{\text {th }}$ of the size of the model particles, the actual amount of dissolved material at the interface is probably larger, because the amount of dissolved material depends on the grain size (equation 6). The scaling relation of Koehn et al. (2007)

$$
A=b\left(\frac{w}{L}\right)^{1 / 0.8} L,
$$

where the prefactor $b$ is 10 (factor varies, see Koehn et al., 2007 and Ebner et al., 2009a), $A$ is the dissolved material $(\mathrm{mm}), w$ the mean RMS width of the interface in millimeter (for details of calculation compare Koehn et al., 2007 and Ebner et al., 2009a)and $L$ the grain size (mm), with a grain size of about $0.01 \mathrm{~mm}$ for the natural example and a mean width of the interface of $2 \mathrm{~mm}$, results in an estimation of roughly $7.5 \mathrm{~cm}$ of material dissolved at the interface or 40

407 times the mean width of the interface. It is thus not possible to deduce the amount of 408 dissolution directly from the finite interface morphology.

\section{Conclusions}

411 We modelled the development of stylolite patterns using a rock matrix that contains either a 412 uniform or a bimodal grain size. Stylolites that developed from a bimodal noise show 
413 pronounced teeth with straight edges and grow linearly with a growth exponent of about 1.0.

414 The morphology produced by the simulations is similar to field observations. The distance 415 between the maximum and minimun height of a tooth above and below the original 416 dissolution surface can be used to estimate compaction if pinning starts relatively early during 417 stylolite growth, and pinning grains are not completely destroyed during successive 418 dissolution, thus giving a value that only slightly underestimates the true dissolution along the 419 interface. Stylolites that develop in a rock that has a noise that sits on a uniform grain size may contain spikes but the height of these asperities highly underestimates compaction. For these stylolites the mean width of the interface should be calculated and the scaling law of 422 Koehn et al. (2007) should be used to estimate compaction.

423 Modelling the growth of stylolites that developed under different normal stresses shows 424 stylolite patterns that can be best distinguished using statistical methods. We use the Fourier method to extract the cross-over length scale from the numerical stylolites, calculate the predicted theoretical vertical stress values and compare them with the actual values used in the numerical simulations. The results are consistent and we can show that the numerical model reproduces the proposed scaling relation, thus our numerical model gives an independent confirmation of the analytical solution of Schmittbuhl et al. (2004). This analytical solution to determine paleo-stress magnitudes from stylolite shapes seems to be robust: the analytical result is verified for sets of stylolites obtained with two independent techniques, namely the ones produced with the current numerical model, and natural examples investigated by Ebner et al. (2009), whose burial stresses were inferred from their relative position in the stratigraphic column. To summarize, comparing numerical simulations with the stylolite shown on Figure $1 \mathrm{~b}$ indicates that this stylolite formed during burial in a basin, at depth close to $1400 \mathrm{~m}$, and accommodated about $7.5 \mathrm{~cm}$ of dissolution. 
Koehn and Ebner acknowledge funding by the DFG (KO 2114/5). Toussaint and Renard

acknowledge support of a FORPRO CNRS/ANDRA grant.

Aharonov, E., Katsman, R., 2009. Interaction between pressure solution and clays in stylolite development: insights from modeling. American Journal of Science 309, 7, 607-632.

Barabasi, A. L., Stanley, H. E., 1995. Fractal concepts in surface growth. Cambridge University Press.

Baron M., Parnell J., 1979. Relationships between stylolites and cementation in sandstone reservoirs: Examples from the North Sea, UK and East Greenland. Sedimentary Geology 194, 17-35.

Beach, A., 1979. Pressure solution as a metamorphic process in deformed terrigenous sedimentary rocks. Lithos 12, 51-58.

Bons, P. D., Koehn, D., Jessell, M. W., 2008. Microdynamics Simulation. In: Lecture Notes in Earth Sciences 106. Springer, Berlin.

Brouste, A., Renard, F., Gratier, J. P., Schmittbuhl, J., 2007. Variety of stylolites' morphologies and statistical characterization of the amount of heterogeneities in the rock. Journal of Structural Geology 29, 422-434.

Burkhard M., 1993. Calcite twins, their geometry, appearance and significance as stress-strain markers and indicators of tectonic regime: a review. J. Struct. Geol. 15, 3-5, 351-368.

Clark, S. P. J., 1966. Handbook of Physical Constants. Geological Society of America, New York.

Dunnington, H. V., 1954. Stylolite development post-dates rock induration. Journal of sedimentary Petrology 24, 27-49.

Ebner, M., Koehn, D., Toussaint, R., Renard, F., 2009a. The influence of rock heterogeneity on the scaling properties of simulated and natural stylolites. Journal of Structural Geology 31, 72-82.

Ebner, M., Koehn, D., Toussaint, R., Renard, F., Schmittbuhl, J., 2009b. Stress sensitivity of stylolite morphology. Earth and Planetary Science Letters 277, 394-398.

Ebner, M., Toussaint, R., Schmittbuhl, J., Koehn, D., Bons, P. 2010a. Anisotropic scaling of tectonic stylolites: a fossilized signature of the stress field? J. Geophys. Res. 115, B06403.

Ebner, M., Piazolo, S.,Renard, F., Koehn, D., 2010b. Stylolite interfaces and surrounding matrix material: Nature and role of heterogeneities in roughness and microstructural development. Journal of Structural Geology 32, 1070-1084.

Fabricius, I.L., Borre, M.K., 2007. Stylolites, porosity, depositional texture and silicates in chalk facies sediments. Ontong Java Plateau - Gorm and Tyra fields, North Sea. Sedimentology 54, 183-205.

Fletcher, R. C., Pollard, D. D., 1981. Anti-Crack Model for Pressure Solution Surfaces. Geology 9, 419-424.

Gratier, J. P., Muquet, L., Hassani, R., Renard, F., 2005. Experimental microstylolites in quartz and modeled application to natural stylolitic structures. Journal of Structural Geology 27, 89-100.

Guzzetta, G., 1984. Kinematics of Stylolite Formation and Physics of the Pressure-Solution Process. Tectonophysics 101, 383-394.

Heald, M. T., 1955. Stylolites in Sandstones. Journal of Geology 63, 101-114. 
Katsman, R., Aharonov, E., Scher, H., 2006. A numerical study on localized volume reduction in elastic media: some insights on the mechanics of anticracks, JGR, 111, B3, B03204.

Karcz, Z. Scholz, C. H., 2003. The fractal geometry of some stylolites from the Calcare Massiccio Formation, Italy. Journal of Structural Geology 25, 1301-1316.

Koehn, D., Arnold, J., Jamtveit, B., Malthe-Sørenssen, A., 2003. Instabilites in stress corrosion and the transition to brittle failure. American Journal of Science 303, 956971.

Koehn, D., Malthe-Sørenssen, A., Passchier, C.W., 2006. The structure of reactive grain boundaries under stress containing confined fluids. Journal of Chemical Geology 230, 207-219.

Koehn, D., Renard, F., Toussaint, R., Passchier, C. W., 2007. Growth of stylolite teeth patterns depending on normal stress and finite compaction. Earth and Planetary Science Letters 257, 582-595.

Lacombe, O., 2010. Calcite Twins, a Tool for Tectonic Studies in Thrust Belts and Stable Orogenic Forelands, Oil \& Gas Science and Technology - Rev. IFP Energies nouvelles, 65, 809-838.

Merino, E., 1992. Self-organization in stylolites. American Scientist 80, 466.

Park, W. C., Schot, E. H., 1968. Stylolites: their nature and origin. Journal of sedimentary Petrology 38, 175-191.

Petit, J. P., Mattauer, M., 1995. Paleostress Superimposition Deduced from Mesoscale Structures in Limestone - the Matelles Exposure, Languedoc, France. Journal of Structural Geology 17, 245-256.

Railsback, L. B., 1993. Lithologic Controls on Morphology of Pressure-Dissolution Surfaces (Stylolites and Dissolution Seams) in Paleozoic Carbonate Rocks from the Mideastern United-States. Journal of Sedimentary Petrology 63, 513-522.

Renard, F., Schmittbuhl, J., Gratier, J. P., Meakin, P., Merino, E., 2004. Three-dimensional roughness of stylolites in limestones. Journal of Geophysical Research-Solid Earth 109 (B3).

Rispoli, R., 1981. Stress-Fields About Strike-Slip Faults Inferred from Stylolites and Tension Gashes. Tectonophysics 75, T29-T36.

Rutter, E. H., 1983. Pressure solution in nature, theory and experiment. Journal of the Geological Society of London 140, 725-740.

Schmittbuhl, J., Vilotte, J. P., Roux, S., 1995. Reliability of Self-Affine Measurements. Physical Review E 51, 131-147.

Schmittbuhl, J., Renard, F., Gratier, J. P., Toussaint, R., 2004. Roughness of stylolites: Implications of 3D high resolution topography measurements. Physical Review Letters 93, 238501.

Tada, R., Siever, R., 1989. Pressure Solution during Diagenesis. Annual Review of Earth and Planetary Sciences 17, 89-118.

Figure captions

Figure 1: Example of the same natural stylolite in limestone, at different scales. On the large

scale, the stylolite is relatively flat whereas the aspect ratio of the roughness (out-of-plane

dimension over in-plane one) increases towards smaller scales from a to c. Between c and d

the roughness aspect ratio remains constant. 
532 Figure 2: a) Sketch showing typical stylolite teeth where the sides of the teeth are oriented parallel to the main compressive stress. In the example on the right hand side the teeth are inclined indicating that the main stylolite plane is oriented at an angle to the smallest principle stress $\sigma_{3}$. b) Sketch illustrating how stylolite teeth shown in a) can grow if impurities (dark cirlces) pin the interface. c) Sketch after Ebner et al. (2010b) showing how low solubility quartz grains may pin the sides of teeth in natural stylolites.

Figure 3: Model setups for the numerical simulations of stylolite roughening. The sidewalls

540 are confined and the upper and lower walls are pushed inwards. Dissolution takes place along

541 an initially flat line in the centre of the model. Dark particles dissolve slower. a) Setup for a

542 uniform grain size where the particles in the model may represent grains in the rock. b) Setup

543 for a bimodal grain size, where the small grains are represented by particles in the model

544 whereas the large grains are defined by clusters of particles.

546 Figure 4: Results of the numerical simulations of stylolite roughening for a) a bimodal grain 547 size and b) a uniform grain size. The actual dissolution of the host rock is indicated with grey 548 vertical bars next to the stylolites. On the right hand side two natural stylolites are shown that 549 may represent similar variations in noise than in the simulations. The grey patches along the 550 stylolite indicate the largest grains that dissolve slower and act as pinning sites for the 551 interface. Note the strong similarity between the numerical simulations and the natural 552 stylolites.

554 Figure 5: Time sequence of simulated stylolite growth in a host rock with a bimodal grain 555 size. Note that model steps are proportional to strain increments and amounts of dissolved 556 material and not real time. Bars on the right hand side record the real amount of dissolved 
material in the simulations. Note how largest grains (grey patches) pin the interface and

558 produce pronounced teeth that record accurately the actual compaction.

560 Figure 6: Two sets of 7 stylolites that developed under increasing normal stress. Right and left

561 hand stylolites only differ in initial random seeds of the quenched noise in the simulations.

562 The relationship between the rough geometries and stresses cannot be visualized, even though

563 there may be an increase in spikes from low to high stresses.

565 Figure 7: Fourier analysis of the roughness of stylolites, where the Fourier power spectrum $566(P(k))$ is plotted against the wave-number $(k)$, the inverse of the wavelength of the roughness.

567 a) shows a Fourier analysis of a the natural stylolite shown in figure 1, b) an average of the

568 Fourier analysis of 3 numerical stylolites. c) and d) show binned data sets of the Fourier

569 power spectra of a) and b) and the presence of a well-defined crossover length scale.

571 Figure 8: Plot of the square root of the inverse of the determined crossover length from the

572 numerical simulations against the applied stress following the scaling law of Schmittbuhl et

573 al., (2004). The data plots roughly on a line illustrating that the simulations reproduce the

574 scaling relation. Error bars represent variations in different cross-over length scales found in 575 different simulations. 
Stylolites are stress gauges

Stylolites can be used to estimate compaction

Grain size distribution influences stylolite teeth growth

Stylolites with large pinning fossils grow linear

Stylolites with uniform grain size grow non-linear 
Click here to download high resolution image
Clice

a)

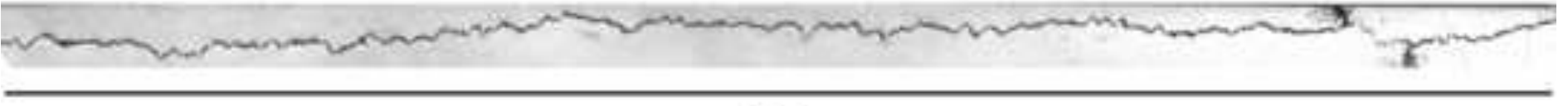

b)

$400 \mathrm{~mm}$

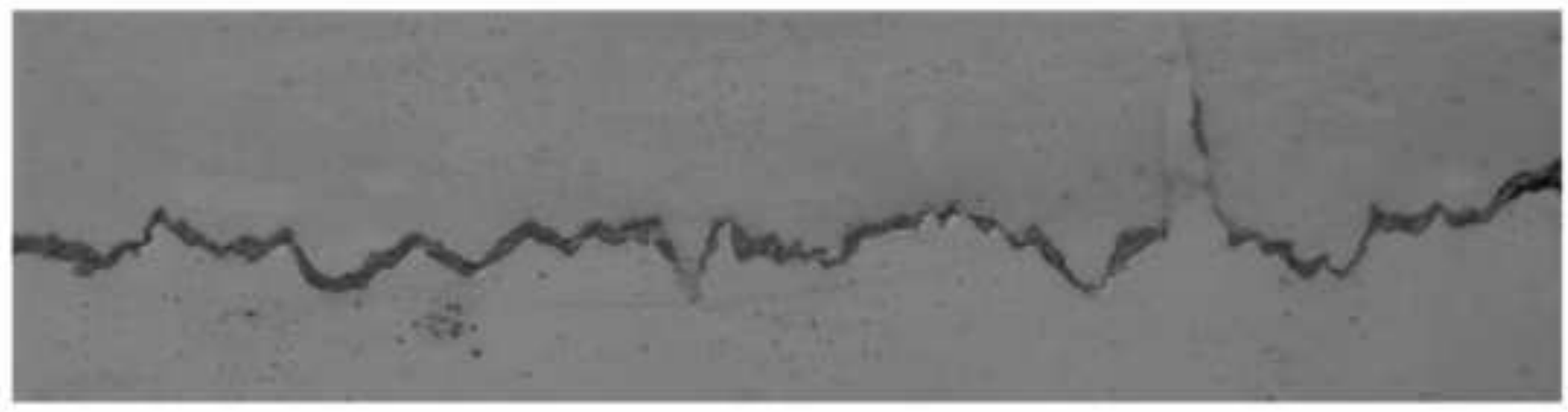

c)

$60 \mathrm{~mm}$

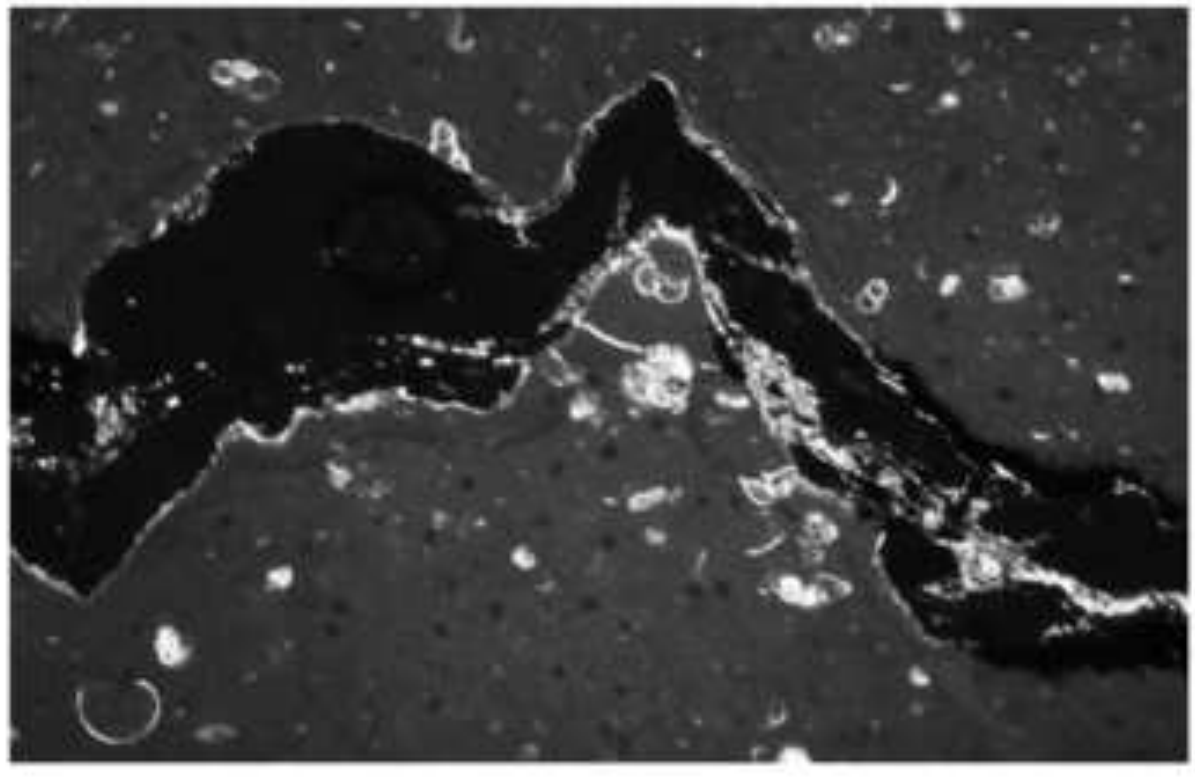

d)

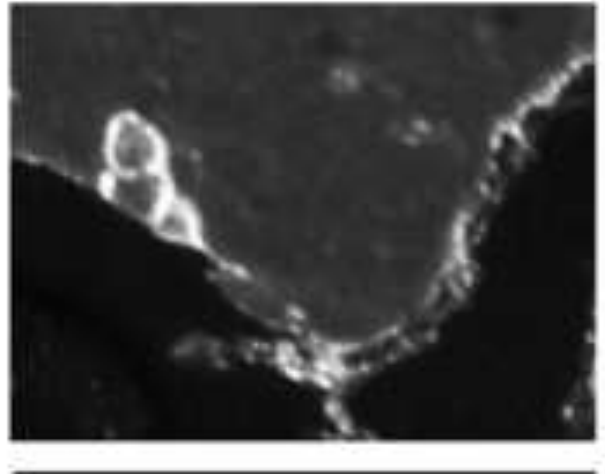

$0.8 \mathrm{~mm}$

$4 \mathrm{~mm}$

Fig. 1 
Figure
Click here to download high resolution image

a)

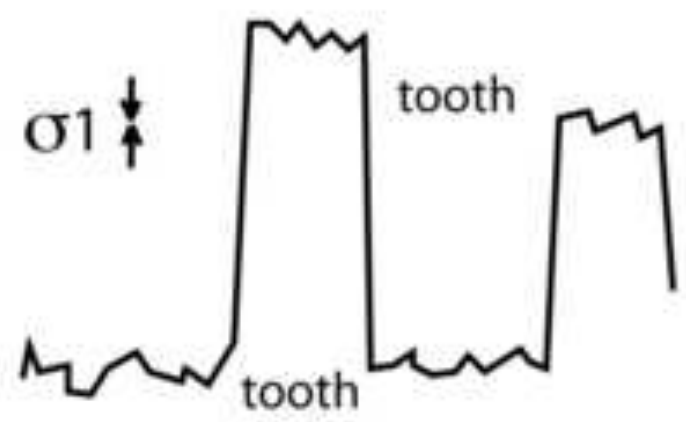

b)
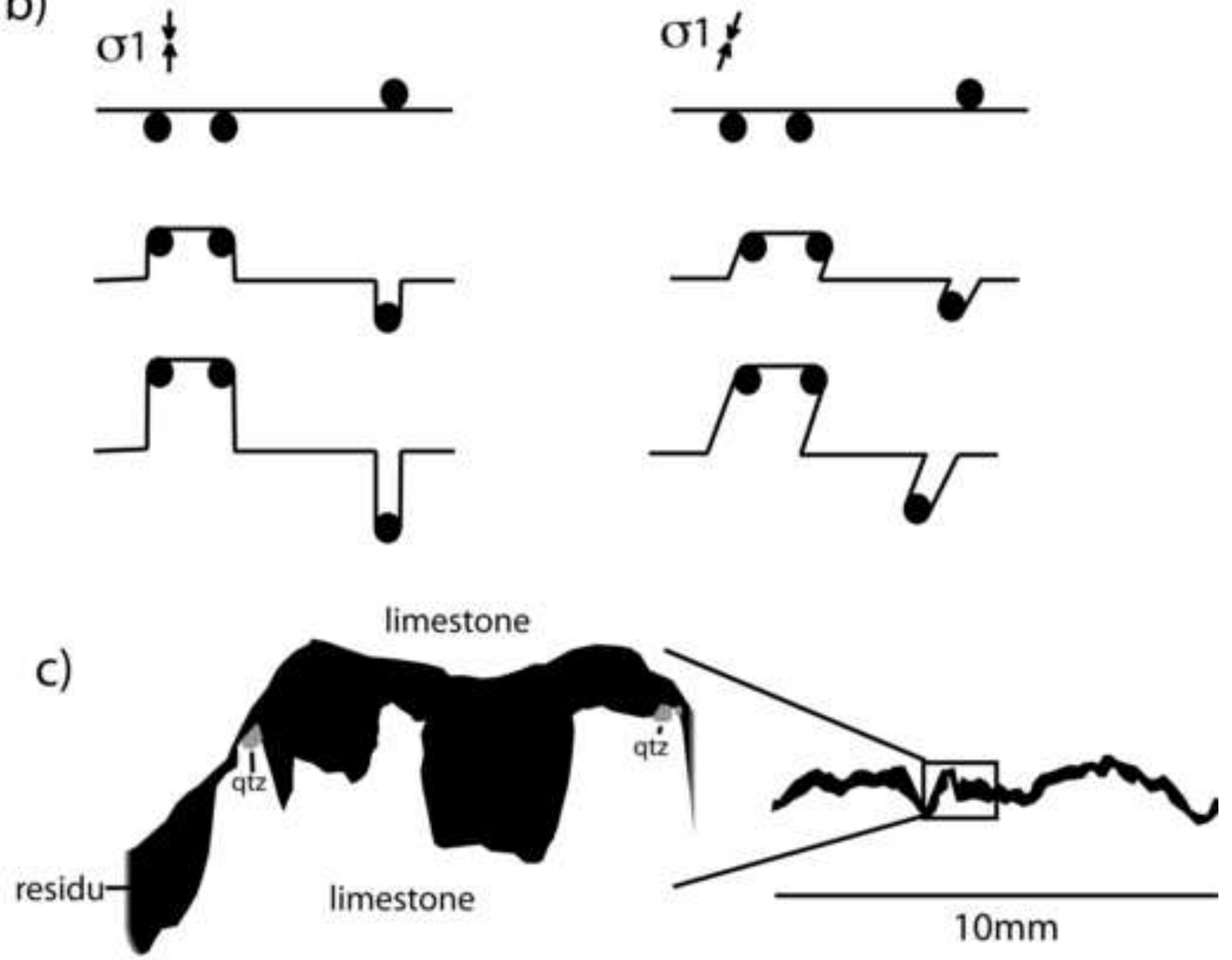

figure 2 

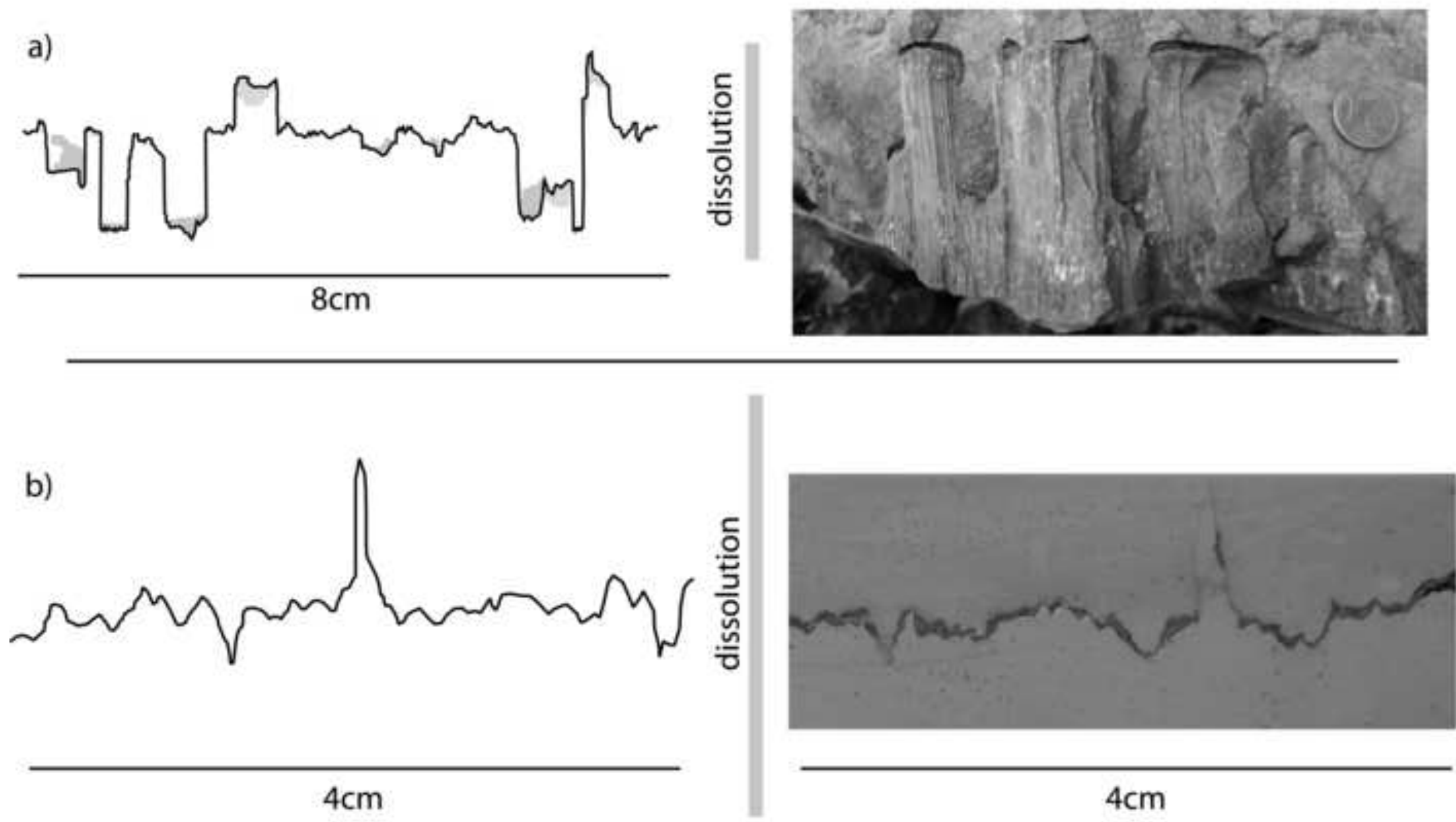

figure 4

$$
4 \mathrm{~cm}
$$




$$
\mathrm{t}=2000
$$

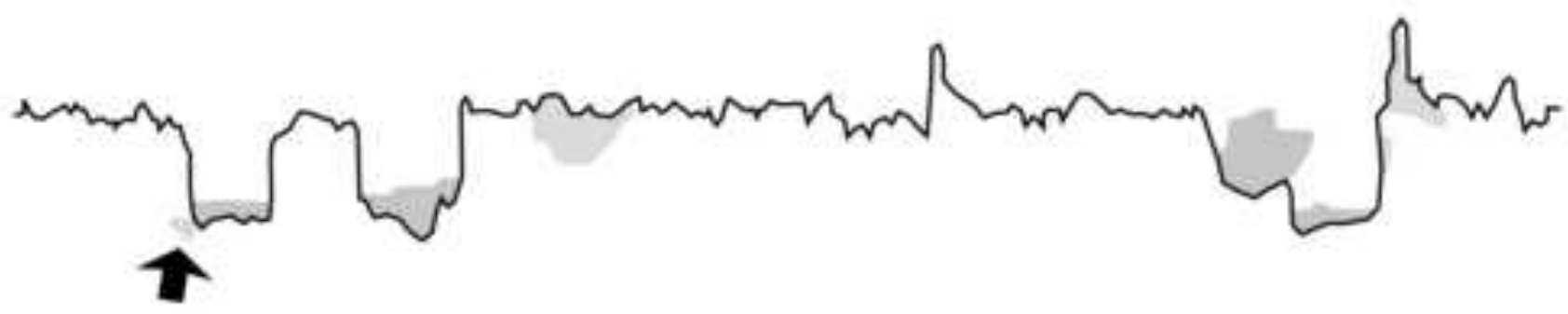

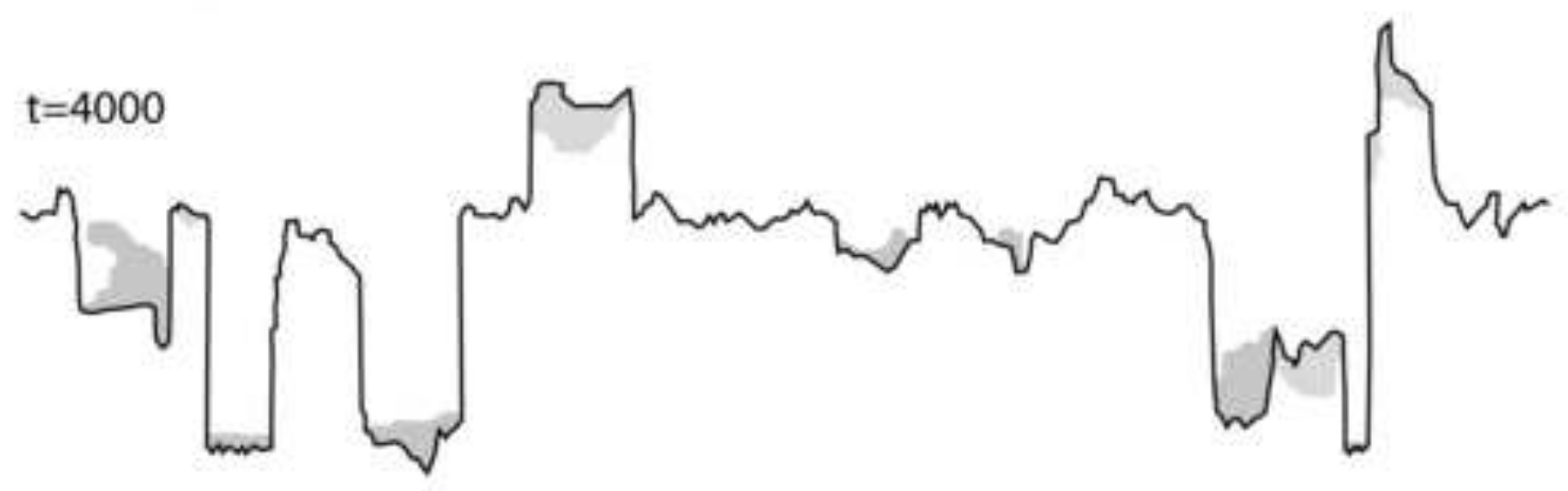

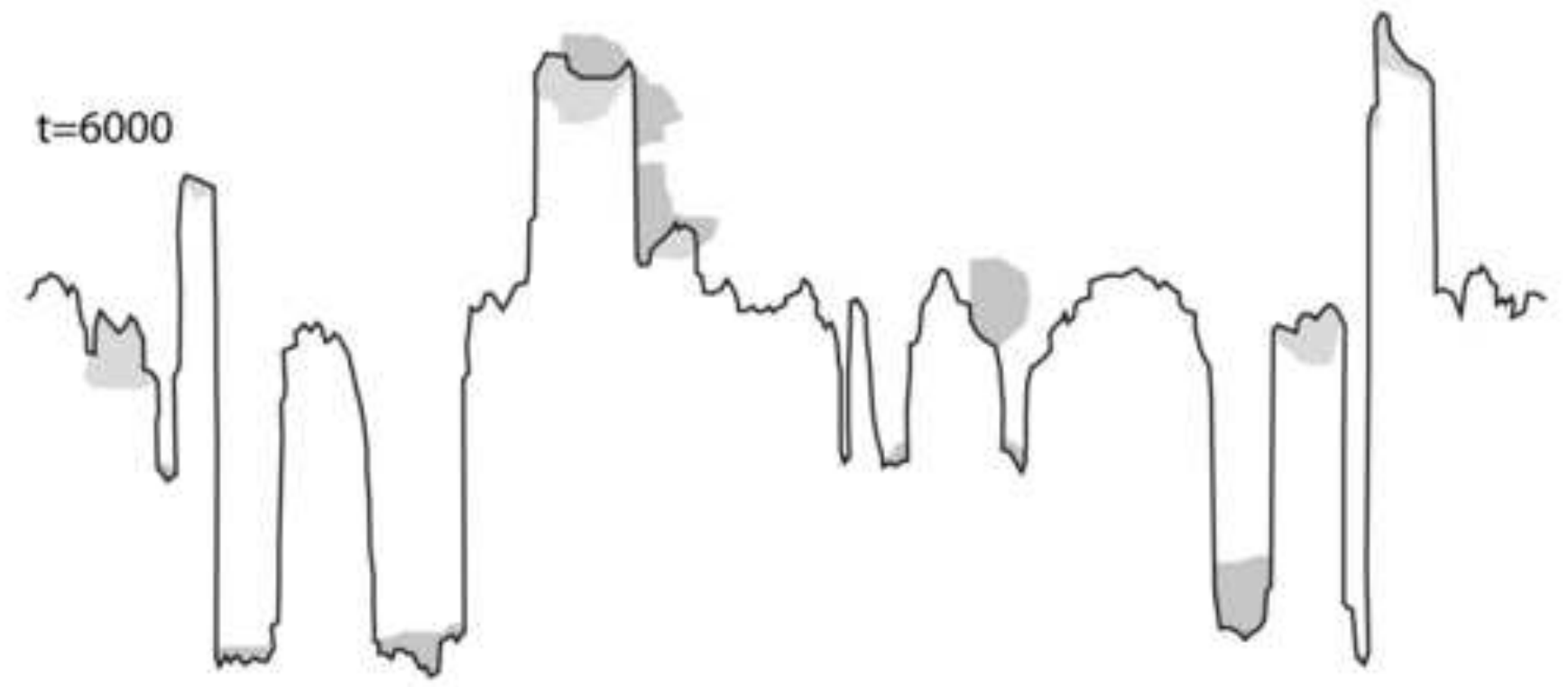

figure 5 


\section{variation in noise}

(29)

figure 6 
natural example

a)

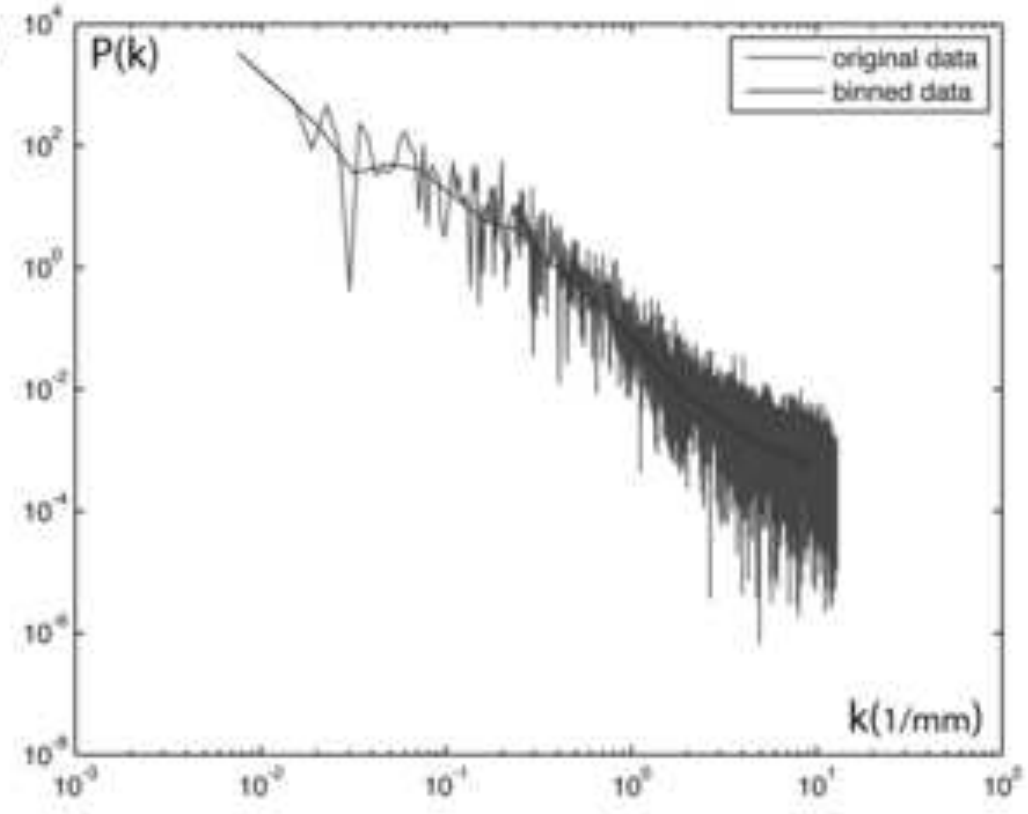

c)

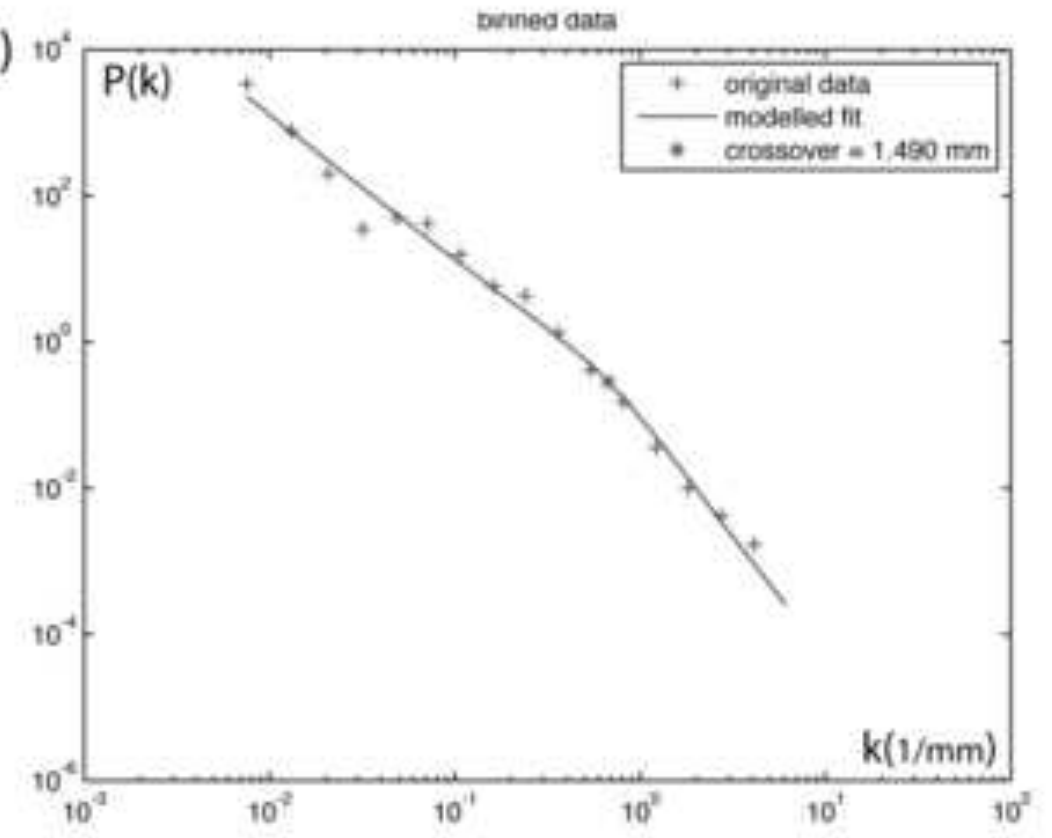

simulation

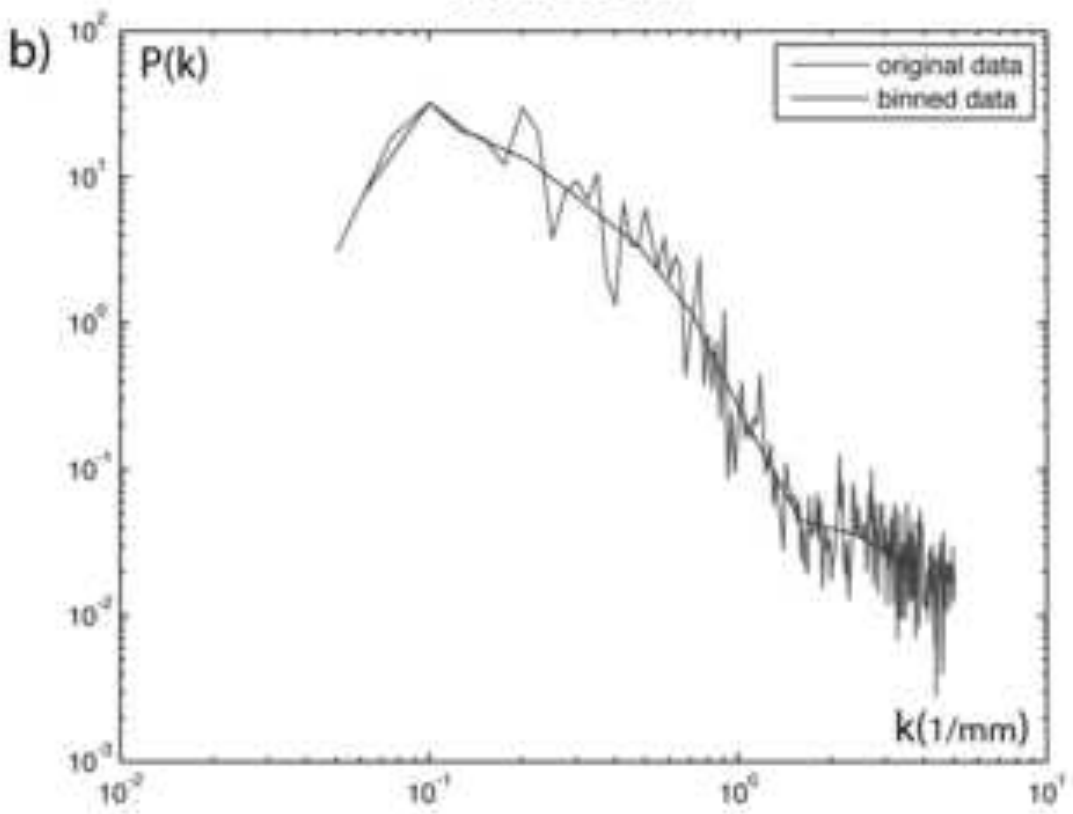

d) 10

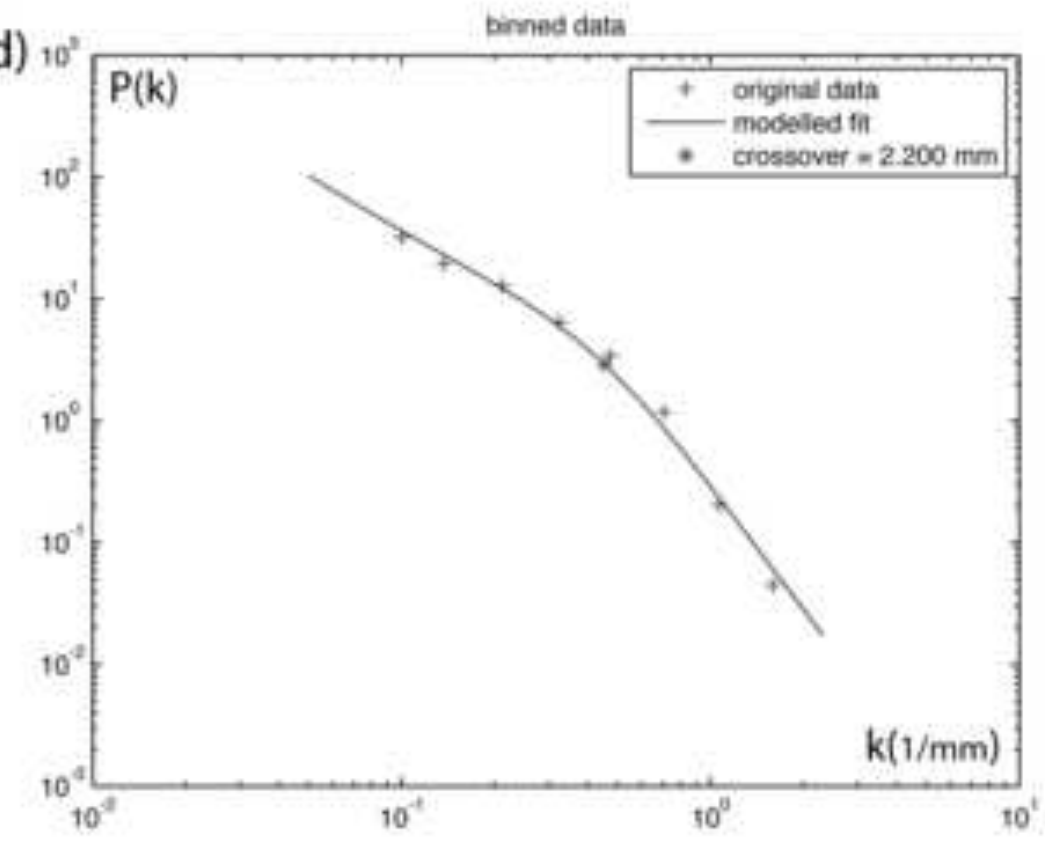

figure 7 
Figure
Click here to download high resolution image

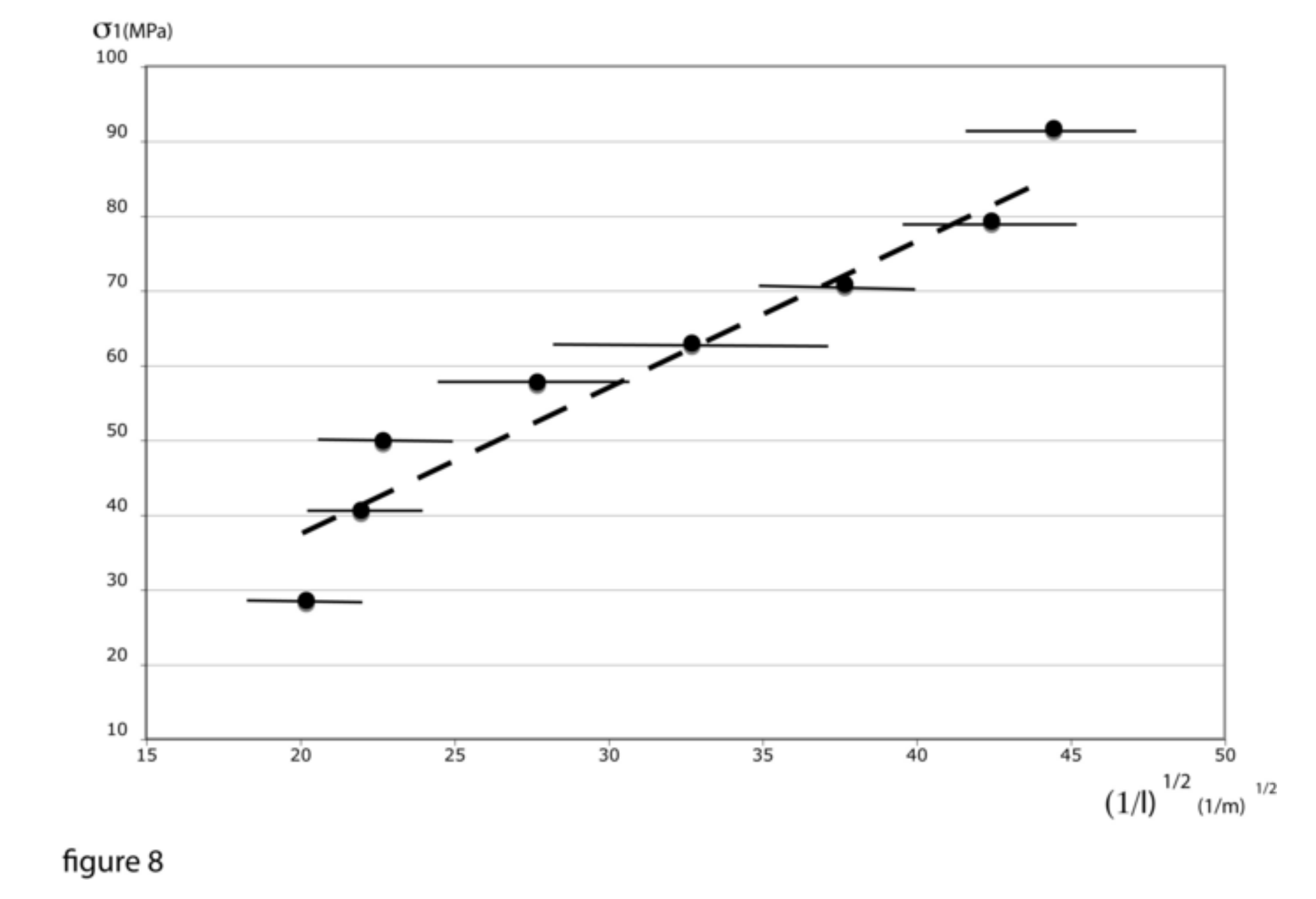

figure 8

.

\footnotetext{
(1)
}

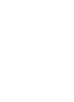

